\title{
Marker concentration patterns of labelled leaf and stem particles in the rumen of cattle grazing bermuda grass (Cynodon dactylon) analysed by reference to a raft model*
}

\author{
D. P. Poppi†, W. C. Ellis $\ddagger$ J. H. Matis§ and C. E. Lascano\| \\ Texas A\&M University College Station, Texas 77843, USA
}

(Received 11 January 2000 - Revised 18 September 2000 - Accepted 10 November 2000)

\begin{abstract}
Large (>1600 $\mu \mathrm{m})$, ingestively masticated particles of bermuda grass (Cynodon dactylon L. Pers.) leaf and stem labelled with ${ }^{169} \mathrm{Yb}$ and ${ }^{144} \mathrm{Ce}$ respectively were inserted into the rumen digesta raft of heifers grazing bermuda grass. The concentration of markers in digesta sampled from the raft and ventral rumen were monitored at regular intervals over approximately $144 \mathrm{~h}$. The data from the two sampling sites were simultaneously fitted to two pool (raft and ventral rumen-reticulum) models with either reversible or sequential flow between the two pools. The sequential flow model fitted the data equally as well as the reversible flow model but the reversible flow model was used because of its greater application. The reversible flow model, hereafter called the raft model, had the following features: a relatively slow age-dependent transfer rate from the raft (means for a gamma 2 distributed rate parameter for leaf $0.0740 v$. stem $0.0478 \mathrm{~h}^{-1}$ ), a very slow first order reversible flow from the ventral rumen to the raft (mean for leaf and stem $0 \cdot 010 \mathrm{~h}^{-1}$ ) and a very rapid first order exit from the ventral rumen (mean of leaf and stem $0.44 \mathrm{~h}^{-1}$ ). The raft was calculated to occupy approximately 0.82 total rumen DM of the raft and ventral rumen pools. Fitting a sequential two pool model or a single exponential model individually to values from each of the two sampling sites yielded similar parameter values for both sites and faster rate parameters for leaf as compared with stem, in agreement with the raft model. These results were interpreted as indicating that the raft forms a large relatively inert pool within the rumen. Particles generated within the raft have difficulty escaping but once into the ventral rumen pool they escape quickly with a low probability of return to the raft. It was concluded that the raft model gave a good interpretation of the data and emphasized escape from and movement within the raft as important components of the residence time of leaf and stem particles within the rumen digesta of cattle.
\end{abstract}

\section{Marker: Residence time: Rumen: Raft: Leaf and stem particles}

Passage of digesta from the rumen is clearly a major determinant of intake of fibre-containing diets (Blaxter et al. 1956; Balch \& Campling, 1962; Ulyatt et al. 1967; Thornton \& Minson, 1973). Measuring rate of passage in terms of mass/h or fractional outflow rate has been an important area of research to explain differences in intake. This has been done in a variety of ways, summarized by Faichney $(1975,1986)$ and Ellis et al. $(1984 a, b)$. The rationale has been to develop techniques that can be used to examine diet effects on digesta passage from the rumen and also to develop models which describe how digesta mixes within and exits from the rumen. The conceptual delineating of pools within the rumen and the quantitative values associated with their turnover enable identification of ratelimiting pathways and how these may interact with forage type and physiological state of the animal in determining intake by the animal.

Models of digesta flow through the rumen have considered rumen digesta to be a homogenous pool (Blaxter et al. 1956; Grovum \& Williams 1973a,b, 1977)

\footnotetext{
Abbreviations: MRT, mean residence time; MRTR, mean residence time in the rumen raft compartment; MRTV, mean residence time in the ventral rumen compartment; VRR, ventral rumen-reticulum.

* Approved for publication by Texas Agricultural Experiment Station as technical article TA2345.

$\uparrow$ Corresponding author: present address School of Land and Food Sciences, The University of Queensland, Q.4072, Australia, fax +61 73365 1177, email d.poppi@mailbox.uq.edu.au

† Present address: Animal Science Department, Texas A\&M University, College Station, TX 77843, USA.

$\S$ Present address: Department of Statistics, Texas A\&M University College Station, TX 77843, USA.

|| Present address: CIAT, Apartado Aereo G713 Cali, Colombia, South America.
} 
or one with a gradation of particle size pools often separated for convenience into large and small particle pools (Hungate, 1966; Baldwin et al. 1976; Poppi et al. 1981; Egan \& Doyle, 1984; Faichney, 1986; Ellis et al. 1984b; Czerkawski, 1986; Ulyatt et al. 1986; Waghorn et al. 1986; Kennedy \& Murphy, 1988). Sutherland (1988) has suggested an alternative concept to particle size pools to examine digesta movement through the rumen and to explain why only small particles escape. This is that particles separate into those having buoyant properties acquired via entrapped fermentation gases (newly ingested and especially large particles of stem) and those having sedimentation properties (have been largely digested and tend to be small particles). Flotation results in raft formation and entrapment of particles. Raft, in this context, refers to a pool of particles of varying size which float, but which by the nature of the constraints of the rumen are in contact with each other, cannot separate easily into distinct particles and form a pliable mass.

The concept of buoyant related pools was used to formulate a two-pool rumen digesta model comprising a raft pool (raft digesta low escape potential) and an escape pool (ventral rumen-reticulum (VRR) digesta, high escape potential) with an added feature that particles from the escape pool could return to the raft pool. This is not a feature in the sequential particle size pools in previous models (Baldwin et al. 1976; Poppi et al. 1981; Ellis et al. 1984b; Faichney 1986). Large masticated particles $(>1600 \mu \mathrm{m})$ of leaf and stem were labelled with ${ }^{169} \mathrm{Yb}$ and ${ }^{144} \mathrm{Ce}$, dosed into the rumen digesta raft and the concentration of these markers in the raft and ventral rumen was followed (Lascano, 1979; Ellis et al. 1982, 1985). The concentrations at the two sites were simultaneously fitted to determine rate parameters for flow between and out of two pools with low and high escape potential particles. This approach enabled a number of models to estimate kinetic parameters to be compared and also to prepare a means by which Sutherland's model may be parameterized.

\section{Materials and methods}

\section{Animals, forage and markers}

The data were obtained by Lascano (1979) in a grazing study designed to determine effects of maturity and selective grazing of Coastal bermuda grass (Cynodon dactylon L. Pers) upon forage intake and kinetics of particle size reduction in and escape from the reticulorumen (Ellis et al. 1984b, 1994). Four plots each of three different maturities (20, 33 and 42 d regrowth plots) were each sequentially grazed for $2 \mathrm{~d}$ by successively grazing animals (A, B and C grazers) on two occasions. An average grazing pressure of $22.5 \mathrm{~kg}$ pasture DM/100 kg live weight resulted. A $6 \mathrm{~d}$ measurement period followed a $14 \mathrm{~d}$ period of adjustment to each treatment (three maturities and three successive grazers) during two occasions (n 18).

The 8-10-month-old Brahman $\times$ Jersey heifers (mean $309 \mathrm{~kg}$ live weight) had previously established oesophageal and ruminal cannulas (Ellis et al. 1984b). Prior to each measurement period, samples of the ingestively masticated forage were collected from each animal, freeze-dried and sieved through successive sieves of 3350, 1600 and $100 \mu \mathrm{m}$ apertures. Negligible particles were retained by the $3350 \mu \mathrm{m}$ aperture sieves. Particles retained by the $1600 \mu \mathrm{m}$ aperture sieve were separated into leaf and stem, extracted for $1 \mathrm{~h}$ with a neutral detergent solution without the chelating agent, and thoroughly washed with water and acetone. Following drying at $60^{\circ} \mathrm{C}, 14.78 \mathrm{MBq}^{144} \mathrm{CeCl}_{3}$ or ${ }^{169} \mathrm{YbCl}_{3}$ were sprinkled onto 60-170 g extracted stem and leaf fractions respectively and allowed to air dry for $24 \mathrm{~h}$ before dosing. Some marker may migrate from the particles after this procedure but this is likely to be small.

The ${ }^{144} \mathrm{Ce}$ - and ${ }^{169} \mathrm{Yb}$ - labelled fractions were dosed via a rumen cannula into the dorsal rumen strata of each animal during mid-morning when the animals were ruminating following their usual intense morning period of grazing. A cavity approximately $10 \mathrm{~cm}$ wide and $20 \mathrm{~cm}$ deep was excavated within the dorsal rumen digesta impinging onto the interior orifice of the $10 \mathrm{~cm}$ rumen cannulas. After dosing into the cavity, the excavated digesta was returned. Samples of dorsal rumen digesta were subsequently collected from the depository site of marked particles at 4, 8, 16, 20, 24, 28, 40, 48, 64, 72, 88, 96, 112, 120, 136, and $144 \mathrm{~h}$ after the dose.

Following collection of dorsal digesta, samples of the ventral rumen digesta were collected via a $2.54 \mathrm{~cm}$ internal diameter plastic pipe inserted through the dorsal rumen digesta to the floor of the ventral sac of the rumen. The pipe was stoppered, withdrawn and its initial digesta sample discarded. The pipe was reinserted to the floor of the ventral sac through the digesta tunnel remaining from the initial insertion. The tube was withdrawn 4-6 cm and digesta allowed to flow into the pipe via hydrostatic pressure, stoppered and the sample contained within the tube withdrawn.

Digesta samples were dried, ground, 1.0-1.5 g samples ashed and the ${ }^{144} \mathrm{Ce}$ and ${ }^{169} \mathrm{Yb}$ dissolved in $50 \mathrm{ml} 3 \mathrm{M}-$ $\mathrm{HNO}_{3}$. A $7 \mathrm{ml}$ aliquot was assayed using a multichannel $\gamma$ spectrometer with a sodium iodide detector. A portion of the labelling solution was simultaneously assayed and used to compute decay-corrected count rate of each radioisotope per g digesta sample DM.

\section{Model development}

Sutherland's concept (1988) relating to particle movement through the rumen can be represented simply as a two-pool model involving turnover of particles from raft and ventral rumen-reticulum pools. Based on the biological characteristics described by Sutherland (1988), the escape rate from the raft pool was assumed to increase as digestion of particles approached their potential for digestion. Such 'age-dependent' escape rates were modelled by assuming that the distribution of elapsed time during a single visit, i.e. 'the retention times', of particles in the raft pool is an integer gamma of 2 or greater (Matis, 1984; Pond et al. 1988). Under this assumption, the initial escape rate at $t 0$ was zero, and after infinite ageing, equals some constant that we denote as $\lambda_{1}$. Models with gamma 2 and gamma 3, denoted $\mathrm{G} 2$ and $\mathrm{G} 3$, retention times were investigated. In the model with $\mathrm{G} 2$, the raft pool may be represented for mathematical convenience as two sequential, homogenous compartments, $\mathrm{R}_{1}$ and $\mathrm{R}_{2}$, as given in Fig. 1 . In the model 


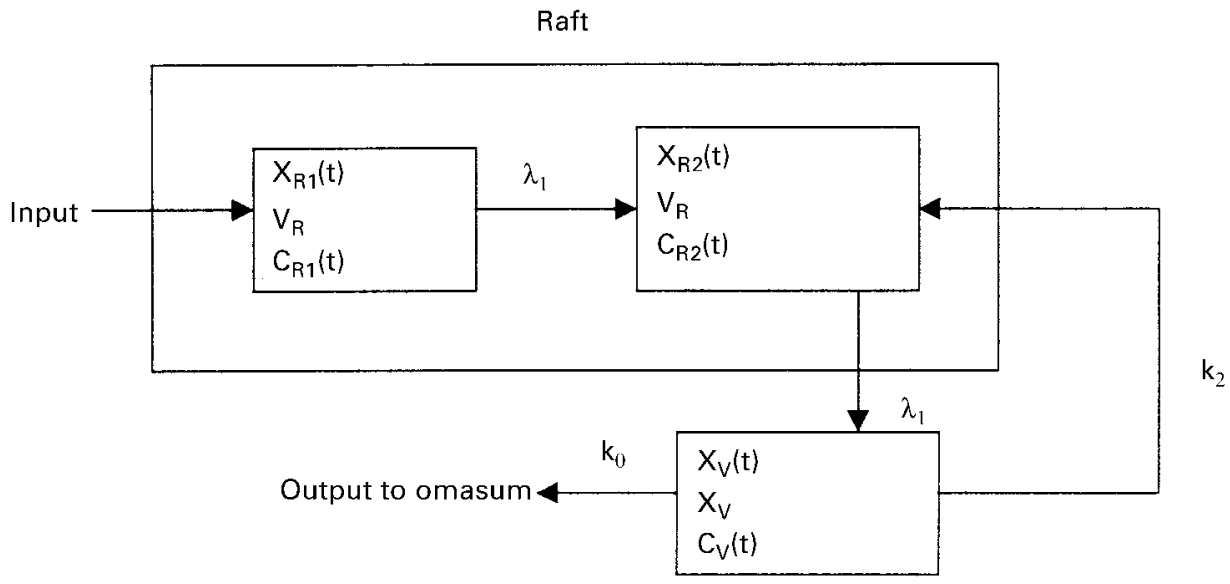

Ventral rumen-recticulum

Fig. 1. Flow of particles or markers through the rumen. The raft is considered as a pool of two sequential compartments, $R_{1}$ and $R_{2}$, representing conceptual dosing and sampling sites respectively which are embedded in the same volume, $V_{R}$. The rate parameter, $\lambda_{1}$ describes agedependent turnover flow from the raft pool to the ventral rumen-reticulum compartment, $v$. Mass action, age independent turnover from $v$ is via exit to the omasum or by recycling back into the sampling compartment of the raft pool, $R_{2}$, and return via rate $\lambda_{1}$. The quantities, $X$, and concentration, $\mathrm{C}$, of marker in each compartment's volume, $\mathrm{V}$, is indicated as a function of time.

with $\mathrm{G} 3$, the raft pool would be represented for subsequent mathematical analysis using three homogenous compartments. In either case, the sequence of homogenous compartments does not imply a physical partitioning of the raft pool; rather the sequence produces mathematically a combined effect, which yields the age-dependent distributed retention times that ingested particles spent in the raft pool prior to their escape.

Particles escaping the raft pool enter the VRR which, due to its rather uniform composition, is considered a homogenous compartment. Escape from the VRR compartment is by flow either to the omasum or return to the fermentatively spent, small particle compartment of the raft pool. Both are mass action processes and hence are represented with age-independent escape rates, $\mathrm{k}_{0}$ and $\mathrm{k}_{2}$ respectively, which imply exponentially distributed retention times (G1). Subsequent escape of the fermentatively spent, small particles recycled back into the raft compartment is via mass action, which yields an age-independent rate. This escape rate under the previous assumptions is $\lambda_{1}$ and it is implemented into both the G2 and G3 models by recycling the particles into the second compartment, $\mathrm{R}_{2}$, of the raft pool (Fig. 1). The two proposed reversible flow

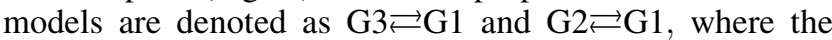
mass action passage of the recycled particles is understood.

No assumption is made as to what are the escape characteristics of particles from the rumen, but Sutherland (1988) has noted that the ability to sediment is a necessary characteristic for particles to get into the appropriate digesta stream(s) to reach the omasal orifice and that this is related to the extent of digestion of the particle and its particle size.

\section{Model equations}

Solutions relating to the equations for the $\mathrm{G} 2 \rightleftarrows \mathrm{G} 1$ model are given in the Appendix (p. 563). The equations for the $\mathrm{G} 3 \rightleftarrows \mathrm{G} 1$ model are similar.
The equations used for $\mathrm{G} 2 \rightleftarrows \mathrm{G} 1$ are:

$$
\begin{gathered}
\dot{\mathrm{C}}_{\mathrm{R} 1}(\mathrm{t})=-\lambda_{1} \mathrm{C}_{\mathrm{R} 1}, \\
\dot{\mathrm{C}}_{\mathrm{R} 2}(\mathrm{t})=-\lambda_{1} \mathrm{C}_{\mathrm{R} 2}+\lambda_{1} \mathrm{C}_{\mathrm{R} 1}+\mathrm{k}_{2} \mathrm{r} \mathrm{C}_{\mathrm{v}}, \\
\dot{\mathrm{C}}_{\mathrm{v}}(\mathrm{t})=-\left(\mathrm{k}_{0}+\mathrm{k}_{2}\right) \mathrm{C}_{\mathrm{v}}+\lambda_{1} \mathrm{C}_{\mathrm{R} 2} / \mathrm{r}, \\
\operatorname{MRTR}=\left(2 \mathrm{k}_{0}+\mathrm{k}_{2}\right) /\left(\mathrm{k}_{0} \lambda_{1}\right), \\
\operatorname{MRTV}=\mathrm{k}_{0}^{-1},
\end{gathered}
$$

where $\mathrm{k}_{0}, \lambda_{1}, \mathrm{k}_{2}$ are rate parameters, $\mathrm{r}$ is ratio of quantities (ventral rumen:raft); $\mathrm{C}_{\mathrm{R} 1}, \mathrm{C}_{\mathrm{R} 2}, \mathrm{C}_{\mathrm{v}}$ are concentrations at dosing and sampling sites in raft and in the ventral rumen with derivatives $\dot{\mathrm{C}}_{\mathrm{R} 1}(\mathrm{t}), \dot{\mathrm{C}}_{\mathrm{R} 2}(\mathrm{t})$ and $\dot{\mathrm{C}}_{\mathrm{v}}(\mathrm{t})$; and MRTR, MRTV are mean residence times in raft and ventral rumen compartments respectively.

The observed concentrations in the raft were ascending initially, which indicated that the sampling site was different from the dosing site (Fig. 2). For simplicity, the sampling site was assumed to be the $\mathrm{R}_{2}$ compartment in the rumen raft pool. Therefore, the two regression functions fitted to the data were $\mathrm{C}_{\mathrm{R} 2}(\mathrm{t})$ and $\mathrm{C}_{\mathrm{v}}(\mathrm{t})$, which were obtained numerically using computer software.

The statistical package PCNONLIN (CM Metzler and DL Weiner; PCNONLIN Nonlinear estimation program, 1986, Statistical Consultants, Inc., Lexington, KY, USA) was used. The marker concentration data from the dorsal and the ventral rumen were fitted simultaneously, which enabled estimation of the relative size of raft and VRR pools. The sensitivity of parameter estimates to the starting values was also examined. This is a robust procedure allowing parameter estimates not possible previously.

\section{Alternative models}

Instead of having reversible flow between the VRR and the 


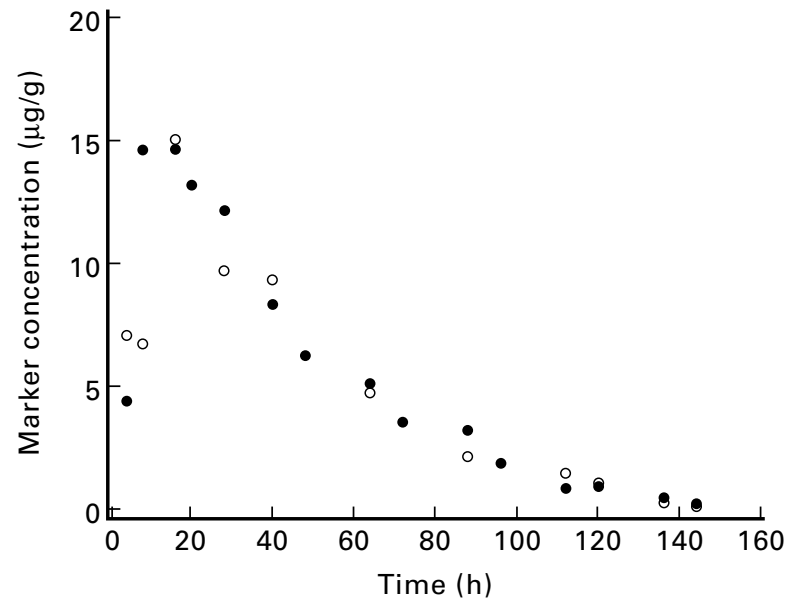

Fig. 2. Observed values in an animal for ${ }^{169} \mathrm{Yb}$ in the dorsal rumen, $(\bullet)$, and ventral rumen, $(\bigcirc)$, following dosing into the dorsal rumen. Note the time lag in mixing before disappearance. For details of procedures, see p. 554 .

raft a sequential flow model may be assumed and the data fitted simultaneously using PCNONLIN (Statistical Consultants, Inc.). This can be designated the $\mathrm{G}_{\mathrm{n}} \rightarrow \mathrm{G}_{1}$ model.

In many studies of marker kinetics in the rumen only, the descending portion of the concentration curve is examined and assumed to represent the slow turnover pool of major biological importance (Grovum \& Williams 1973b; Cruickshank et al. 1990). This was also examined here using the Procedure NLIN of SAS (1986; Statistical Analysis Systems Inc. Cary, NC, USA) for fitting the G2 $\rightarrow$ G1 model to data from each sample site independently as distinct from the simultaneous fitting procedure used earlier. The model representation as $G_{n} \rightarrow G_{1}$ is the same.

In addition, a simple procedure of linear regression with the starting value selected visually at a point away from the peak, where concentration was definitely descending, was also analysed. The rate parameter, k, was estimated by linear regression of the equation:

$$
\ln \mathrm{A}(\mathrm{t})=\ln \mathrm{A}(0)-\mathrm{kt},
$$

where $\mathrm{A}(\mathrm{t})$ is the marker concentration at time $\mathrm{t}$ and $\mathrm{A}(0)$ is the marker concentration at time $t_{0}$. This can be represented as a $\mathrm{G}_{1}$ model.

\section{Statistical procedures}

The procedure GLM of SAS (Statistical Analysis Systems Inc.) was used to test effects of forage part (leaf or stem), order of grazer (A, B or C), period (six combinations of three maturities $\times$ two cycles) and some interactions upon the parameters estimated for individual data sets by the models. The ANOVA model is: response $=$ part + grazer + period $+($ part $\times$ grazer $)+($ grazer $\times$ period $)+$ error.

\section{Summary of models used}

Eight models were fitted to the data. Four models were used when the data were fitted simultaneously to marker concentration data from the raft and ventral rumen. The simultaneous fitting procedure is novel, robust and enables estimates of relative pool sizes to be determined. The four models were a gamma 2 or gamma 3 order of age dependency with reversible flow, designated as G2 $\rightleftarrows \mathrm{G} 1$ or G3 $\rightleftarrows \mathrm{G} 1$, or without reversible flow, designated as G2 $\rightarrow$ $\mathrm{G} 1$ or G3 $\rightarrow \mathrm{G} 1$. In addition, the G2 $\rightarrow$ G1 sequential flow model was fitted independently to the concentration data from each sample site. Finally, the simple one-pool exponential model, designated G1, was fitted only to the descending marker concentration data of each sample site.

\section{Results \\ Choice of model}

The $\mathrm{G} 2 \rightleftarrows \mathrm{G} 1$ model consistently fitted all data better than the G3 $\rightleftarrows \mathrm{G} 1$ model as judged by the combined error mean square values and plot of actual $v$. predicted values. However, there was no major difference, using these criteria, to separate the reversible flow models and the sequential flow models fitted simultaneously to the two sample sites. The reversible flow model was accepted purely on the basis that such a phenomenon as flow of particles from the ventral rumen to the raft is known to occur (Ehrlein, 1979; Deswysen \& Ehrlein, 1981; Sutherland, 1988) and that solutions to the model in this form would have more general application. For these reasons,

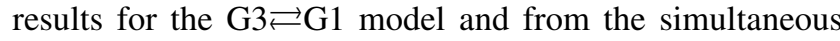
fitting of site data in the sequential G3 $\rightarrow \mathrm{G} 1$ and G2 $\rightarrow \mathrm{G} 1$ models are not presented. Data for the G2 $\rightarrow$ G1 and G1 models fitted separately to each site are presented in Table 1.

\section{Parameter estimates}

The parameter estimates relating to the $\mathrm{G} 2 \rightleftarrows \mathrm{G} 1$ model are summarized in Table 1 where they are presented within treatments. In all cases the order of the rate constants was $\mathrm{k}_{0}>\lambda_{1}>\mathrm{k}_{2}$ with at least a 3-fold difference between these rate parameters, where $k_{0}$ is the rate constant for disappearance from the VRR, $\lambda_{1}$ for exit raft to VRR and $\mathrm{k}_{2}$ for recycling to raft (Fig. 1). The VRR pool size:raft pool size ratio averaged 0.27 for leaf and 0.16 for stem. The order of the rate parameters is reflected in the mean residence time (MRT) in the various compartments shown in Table 2. The MRTR was much greater than MRTV (leaf 31.1 v. $4.6 \mathrm{~h}$, stem 45.4 v. $4.5 \mathrm{~h}$ ). There were large standard errors in estimating MRTV (e.g. 12.9 (SE 6.19) and 5.4 (SE 15.06) h) but the errors associated with MRTR and the total MRT in the rumen were much lower (e.g. MRTR 27.9 (SE 3.01) h, total MRT 40.8 (SE 5.36) h).

There were no significant differences due to order of grazer (A, B or C) in any parameter for either leaf or stem marked particles. Stem particles had a significantly longer MRTR (stem $45.4 \mathrm{~h}$, leaf $31.1 \mathrm{~h}$ ) but not in the ventral rumen (mean $4.6 \mathrm{~h}$ ) (Table 2).

Analysis of the descending portion of the marker concentration curve in the raft and ventral rumen (model G1) yielded similar estimates for rate parameters, $k$, for both sites (leaf 0.0358 v. 0.0330 , stem $0.0270 v$. 
Table 1. Rate parameters $\left(\lambda_{1}, \mathrm{k}_{0}\right.$ and $\left.\mathrm{k}_{2}\right)$ of leaf and stem particles in the conceptual pools of the G2 $\rightleftarrows \mathrm{G} 1$ model with the ratio DM in the ventral rumen-reticulum (VRR): DM in the raft pools (i.e. VRR/raft) and the faster $\left(\lambda_{1}\right)$ and slower $\left(k_{2}\right.$ and $k$ ) turnover rate parameters estimated independently for the rumen dorsal (raft) and ventral digesta (VRR) sampling sites by G2 $\rightarrow \mathrm{G} 1$ and $\mathrm{G} 1$ models $\dagger$

(Mean values with standard errors of the means for eighteen heifers)

\begin{tabular}{|c|c|c|c|c|c|c|c|c|c|c|}
\hline \multirow[b]{4}{*}{ Plant part and grazer } & \multicolumn{10}{|c|}{ Modelł } \\
\hline & \multicolumn{4}{|c|}{$\mathrm{G} 2 \rightleftarrows \mathrm{G} 1$, raft+VRR } & \multicolumn{4}{|c|}{$\mathrm{G} 2 \rightarrow \mathrm{G} 1$} & \multicolumn{2}{|c|}{ G1 } \\
\hline & \multirow[b]{2}{*}{$\lambda_{1}\left(\mathrm{~h}^{-1}\right)$} & \multirow[b]{2}{*}{$\mathrm{k}_{0}\left(\mathrm{~h}^{-1}\right)$} & \multirow[b]{2}{*}{$\mathrm{k}_{2}\left(\mathrm{~h}^{-1}\right)$} & \multirow[b]{2}{*}{ VRR: raft } & \multicolumn{2}{|c|}{ Raft } & \multicolumn{2}{|c|}{ VRR } & \multirow{2}{*}{$\frac{\text { Raft }}{\mathrm{k}\left(\mathrm{h}^{-1}\right)}$} & \multirow{2}{*}{$\frac{\text { VRR }}{\mathrm{k}\left(\mathrm{h}^{-1}\right)}$} \\
\hline & & & & & $\overline{\lambda_{1}\left(h^{-1}\right)}$ & $\mathrm{k}_{2}\left(\mathrm{~h}^{-1}\right)$ & $\overline{\lambda_{1}\left(h^{-1}\right)}$ & $\mathrm{k}_{2}\left(\mathrm{~h}^{-1}\right)$ & & \\
\hline \multicolumn{11}{|l|}{${ }^{169} \mathrm{Yb}$-labelled leaf } \\
\hline A & 0.072 & 0.38 & 0.007 & 0.21 & 0.244 & 0.054 & 0.237 & 0.039 & 0.043 & 0.032 \\
\hline $\mathrm{B}$ & 0.071 & 0.23 & 0.019 & 0.34 & 0.211 & 0.047 & 0.193 & 0.032 & 0.033 & 0.031 \\
\hline $\mathrm{C}$ & 0.079 & 0.94 & 0.015 & 0.25 & 0.409 & 0.049 & 0.179 & 0.054 & 0.032 & 0.036 \\
\hline Mean & 0.074 & 0.51 & 0.014 & 0.27 & 0.288 & 0.050 & 0.201 & 0.042 & 0.036 & 0.033 \\
\hline \multicolumn{11}{|l|}{${ }^{141} \mathrm{Ce}$-labelled stem } \\
\hline A & 0.054 & 0.46 & 0.015 & 0.17 & 0.499 & 0.028 & 0.234 & 0.024 & 0.035 & 0.036 \\
\hline $\mathrm{B}$ & 0.043 & 0.35 & 0.003 & 0.12 & 0.171 & 0.020 & 0.284 & 0.021 & 0.023 & 0.024 \\
\hline $\mathrm{C}$ & 0.047 & 0.24 & 0.006 & 0.19 & 0.207 & 0.020 & 0.174 & 0.023 & 0.022 & 0.026 \\
\hline Mean & 0.048 & 0.38 & 0.008 & $0 \cdot 16$ & 0.276 & 0.023 & 0.234 & 0.022 & 0.027 & 0.029 \\
\hline RSD & 0.018 & 0.62 & 0.018 & 0.24 & & & & & & \\
\hline SEM & $0.004^{\star}$ & 0.13 & 0.004 & 0.057 & $0.043^{*}$ & $0.005^{\star}$ & 0.043 & $0.005^{\star}$ & $0.002^{*}$ & 0.002 \\
\hline
\end{tabular}

$\mathrm{A}, \mathrm{B}, \mathrm{C}$, order of grazer; $\mathrm{RSD}$, residual standard deviation.

Mean values were significantly different, mean leaf $v$. mean stem variable: ${ }^{*} P<0.05$

$\dagger$ For details of procedures and models, see p. 554.

$\ddagger \lambda_{1}, k_{0}$, and $k_{2}$ are rate parameters for escape from raft, escape from VRR to omasum, and backflow from VRR to raft respectively.

$0.0286 \mathrm{~h}^{-1}$, raft $v$. ventral rumen respectively). These values and their corresponding MRT (i.e. 1/k) were lower than observed for the slow turnover pool (raft) in the G2 $\rightleftarrows \mathrm{G} 1$ model. However, residence time of leaf particles was less than stem particles (mean $29.4 \mathrm{~h} \mathrm{v.} 37.4 \mathrm{~h}$ ) in agreement with the order observed in the $\mathrm{G} 2 \leftrightarrows \mathrm{G} 1$ model. The rate parameter $\mathrm{k}$ estimated by the single pool exponential G1 model was significantly greater for all marked particles in the raft of grazer A than for grazer B or C. The fit of the descending concentration curve to the model equation, $\ln \mathrm{A}(\mathrm{t})=\ln \mathrm{A}(0)-\mathrm{kt}$, was good in most cases with $78 \%$ of all regressions having $r^{2}>0.8$.

The results of the sequential G2 $\rightarrow$ G1 model fitted independently to each data set are also summarized in Table 1. Parameters were similar irrespective of whether they were estimated from marker concentration in the dorsal rumen digesta or the ventral rumen digesta. As with the raft model, the rate constants were larger for leaf particles than for stem particles and this is also seen in the residence time estimates which were larger for stem (Table 2).

Table 2. Compartmental residence time ( $\mathrm{h}$ ) of leaf and stem particles in the raft (MRTR), the ventral rumen-reticulum (MRTV) and the total mean residence time in the compartmental system (MRTT) as estimated by the G2 $\rightleftarrows$ G1 model and similar estimates for dorsal digesta $\left(2 / \lambda_{1}, 1 / k_{2}\right.$ and total mean residence in dorsal digesta (MRTD)) and ventral digesta $\left(2 / \lambda_{1}, 1 / \mathrm{k}_{2}\right.$ and total mean residence in ventral digesta (MRTV)) both estimated by the G2 $\rightarrow \mathrm{G} 1$ model fitted independently to each of the two sites and the retention time in dorsal digesta (DD) and ventral digesta

(VD) estimated by the simple G1 model fitted independently to data from each site $\dagger$

(Mean values with standard errors of the means for eighteen heifers)

\begin{tabular}{|c|c|c|c|c|c|c|c|c|c|c|c|}
\hline \multirow[b]{4}{*}{ Plant part and grazer } & \multicolumn{11}{|c|}{ Model } \\
\hline & \multicolumn{3}{|c|}{$\mathrm{G} 2 \rightleftarrows \mathrm{G} 1$, raft + VRR } & \multicolumn{6}{|c|}{$\mathrm{G} 2 \rightarrow \mathrm{G} 1$} & \multicolumn{2}{|c|}{ G1 } \\
\hline & \multirow[b]{2}{*}{ MRTR } & \multirow[b]{2}{*}{ MRTV } & \multirow[b]{2}{*}{ MRTT } & \multicolumn{3}{|c|}{ Dorsal digesta } & \multicolumn{3}{|c|}{ Ventral digesta } & \multirow{2}{*}{$\frac{D D}{1 / k}$} & \multirow{2}{*}{$\frac{V D}{1 / k}$} \\
\hline & & & & $2 / \lambda_{1}$ & $1 / \mathrm{k}_{2}$ & MRTD & $2 / \lambda_{1}$ & $1 / k_{2}$ & MRTV & & \\
\hline \multicolumn{12}{|l|}{$\overline{{ }^{169} \mathrm{Yb}-\text { labelled leaf }}$} \\
\hline$A$ & 29.5 & $3 \cdot 6$ & $33 \cdot 1$ & $11 \cdot 4$ & 18.5 & 29.9 & $10 \cdot 1$ & $25 \cdot 6$ & $35 \cdot 7$ & $23 \cdot 3$ & 31.0 \\
\hline B & 33.5 & $6 \cdot 1$ & 39.6 & 11.0 & $21 \cdot 3$ & $32 \cdot 3$ & $11 \cdot 8$ & 31.3 & $43 \cdot 1$ & 30.5 & $32 \cdot 3$ \\
\hline C & 30.3 & 4.0 & 34.3 & 7.5 & 20.4 & 27.9 & 14.9 & 18.5 & 33.4 & 31.6 & 27.9 \\
\hline Mean & $31 \cdot 1$ & $4 \cdot 6$ & 35.6 & $10 \cdot 0$ & $20 \cdot 1$ & $30 \cdot 0$ & $12 \cdot 3$ & $25 \cdot 1$ & 37.4 & 28.5 & $30 \cdot 4$ \\
\hline \multicolumn{12}{|l|}{${ }^{141} \mathrm{Ce}-$ labelled stem } \\
\hline A & $42 \cdot 2$ & 4.3 & 46.5 & $9 \cdot 1$ & $35 \cdot 6$ & 44.8 & $9 \cdot 6$ & 41.7 & $51 \cdot 3$ & $28 \cdot 2$ & 27.9 \\
\hline B & 50.6 & 4.0 & 54.6 & $16 \cdot 1$ & $50 \cdot 0$ & $66 \cdot 1$ & 9.4 & 47.6 & $53 \cdot 1$ & $42 \cdot 7$ & 41.8 \\
\hline C & $45 \cdot 2$ & $5 \cdot 1$ & $50 \cdot 3$ & 10.5 & $50 \cdot 0$ & 30.5 & 13.9 & 43.5 & 57.4 & $45 \cdot 0$ & 38.5 \\
\hline Mean & $45 \cdot 4$ & 4.5 & $49 \cdot 8$ & 11.9 & $45 \cdot 3$ & $47 \cdot 1$ & $10 \cdot 9$ & $44 \cdot 3$ & 53.9 & $38 \cdot 6$ & $36 \cdot 1$ \\
\hline RSD & 7.55 & 4.49 & $9 \cdot 68$ & & & & & & & & \\
\hline SEM & $1 \cdot 8^{*}$ & $1 \cdot 1$ & $2 \cdot 3^{*}$ & 1.4 & $3 \cdot 3^{*}$ & $3 \cdot 1^{*}$ & 1.4 & $3 \cdot 3^{*}$ & $3 \cdot 1^{*}$ & $3.5^{\star}$ & $2 \cdot 3$ \\
\hline
\end{tabular}

A, B, C, order of grazer; RSD, residual standard deviation.

Mean values were significantly different, mean leaf $v$. stem variable: ${ }^{\star} P<0.05$.

† For details of procedures and models, see p. 554.

$\ddagger \lambda_{1}$ and $k_{2}$ are rate parameters for escape from raft and backflow from VRR to raft respectively. 
The values for the slow turnover pool in all models are not strictly comparable since they involve different assumptions concerning functional pool size which affect their numerical value as will be discussed subsequently.

\section{Discussion}

The question of which compartmental model to use to describe marker excretion or concentration in various parts of the digestive tract and in faeces has been debated frequently (Faichney \& Boston, 1983; Dhanoa et al. 1985; France et al. 1985; Faichney, 1986; Spillane \& Minson, 1986; Huhtanen \& Kukkonen, 1995; Aharoni et al. 1999). The search for new models continues only in the desire to define more accurately the biological system in operation. New model formulation alone would be of no use unless it alters the way in which the system in question is perceived. It should be clearly recognized that the construction of models of digesta flow are done to identify the biological pathways involved and to provide the mathematical means to quantify transfer of digesta, the latter being important in the examination of diet effects on intake and digestion.

\section{Models, assumptions and linkage of sampling site data}

The three types of models used in the current report have different assumptions and utilize the same data in different ways to provide estimates of residence time. The simplest model, the G1 model, assumes that a single exponential distribution of residence times describes the mass action, diluting effect of particle turnover from the sampling site. Imperfect mixing and effects other than mass action are disregarded by fitting the G1 model only to the descending segment of the data. This is the most commonly used model by biologists in examining the turnover of a marker in a single pool.

In contrast to the $\mathrm{G} 1$ model, the $\mathrm{G} 2 \rightarrow \mathrm{G} 1$ sequential two compartment model assumes that the distribution of residence times at the sampling site is the result of two sequential compartments. These two sequential compartments are distinguished by different quantitative and qualitative attributes of the residence time distributions assumed for each individual compartment, i.e. gamma 2 age-dependent (G2) and exponential (G1). When fitted to data, the $\mathrm{G} 2$ distribution of residence times is associated with the faster turnover compartment while the G1 distribution is associated with the slower turnover compartment (Pond et al. 1988). In the G2 $\rightarrow \mathrm{G} 1$ model, sampling is assumed to be from the G1 compartment and the G2 compartment represents a preceding mixing compartment.

If the assumptions are correct for both the G1 and G2 $\rightarrow$ G1 models, then the mean residence time for the slower residence time distributions, $1 / \mathrm{k}$ and $1 / \mathrm{k}_{2}$ respectively, should be equal since they represent turnover at the sampling site. That $1 / \mathrm{k}$ does not consistently approximate $1 / \mathrm{k}_{2}$ (Table 2) may indicate as incorrect the assumption of a homogenous exponential distribution of residence time in the descending segment of data as estimated by the G1 model. By assuming a 'non-mechanistic', age-dependent compartment to describe the distribution of shorter residence times within the $\mathrm{G} 2$ compartment, the $\mathrm{G} 2 \rightarrow$
G1 model should provide unconfounded estimates of residence time distributions for the longer residence time distributions associated with the age-independent, mass action diluting (exponential, G1) processes.

Ellis et al. (1984b) and Wylie et al. (2000) suggested that the shorter residence time distribution represented by the age-dependent G2 compartment of the G2 $\rightarrow \mathrm{G} 1$ model (2/ $\mathrm{k}_{1}$ ) is the result of several processes affecting the movement (mixing) of particles within the ruminen digesta. Such imperfect mixing results in differences in concentration of marker between dosing and sampling site. In the present study, the dosing and sampling site were the same, i.e. the ruminal cannula. However, ascending values exist in the data indicating that dose and sampling sites within the digesta were obviously not the same even though the two were anatomically the same (Fig. 2). The results suggest that the marked dosed particles migrated away from the dosed site as a bolus and then dispersed back to the dose site which subsequently served as the sample site. In the present data, the mean compartmental residence time associated with these age-dependent processes $\left(2 / \lambda_{1}\right)$ ranged from $7 \cdot 5$ to $16 \cdot 1 \mathrm{~h}$, did not differ due to sampling site nor to marked plant part and averaged $11.3 \mathrm{~h}$ (Table 2).

Without specifying mechanisms, the age-dependent compartment of the $\mathrm{G} 2 \rightarrow \mathrm{G} 1$ model accounts for residence time involving mixing between dosed and sampled sites and the exponentially distributed, age-independent compartment accounts for mass action effected turnover at the sampled site. Thus, the mean residence time associated with marker emergence at (G2) and diluting turnover from (G1), the sampling site, exceeds that estimated from the G1 turnover model. The mean residence time estimated by the $\mathrm{G} 2 \rightarrow \mathrm{G} 1$ system (MRT in the dorsal rumen and MRTV) differed according to the digesta site sampled and plant part marked (Table 2). Differences in mean compartmental residence time in the $\mathrm{G} 2 \rightarrow \mathrm{G} 1$ model system were primarily due to differences in mean compartmental residence time associated with turnover at the sampled site $\left(1 / \mathrm{k}_{2}\right)$. The compartmental mean residence time due to turnover, $1 / \mathrm{k}_{2}$, was slower from the VRR site for ${ }^{169} \mathrm{Yb}$ labelled leaf $(25 \cdot 1$ v. $10 \cdot 1 \mathrm{~h})$, similar for ${ }^{144}$ Ce-labelled stem $(45.3$ v. $44.3 \mathrm{~h})$, and slower for ${ }^{144} \mathrm{Ce}$-labelled stem than ${ }^{169} \mathrm{Yb}$-labelled leaf from both the VRR $(44 \cdot 3$ v. $25 \cdot 1 \mathrm{~h})$ and the raft $(45 \cdot 3$ v. $20 \cdot 1 \mathrm{~h})$.

In contrast to the $\mathrm{G} 1$ and $\mathrm{G} 2 \rightarrow \mathrm{G} 1$ models, which were fitted to each individual sampling site, the $\mathrm{G} 2 \leftrightarrows \mathrm{G} 1$ model (or raft model) was simultaneously fitted to data from both sampling sites which is a new procedure. The mean compartmental residence time for the $\mathrm{G} 2 \leftrightarrows \mathrm{G} 1$ compartmental system (total MRT) was intermediate to that estimated by fitting the $\mathrm{G} 2 \rightarrow \mathrm{G} 1$ to each individually sampled site (MRT in the dorsal rumen and MRTV, Table $2)$. Differences between MRT in the dorsal rumen and MRTV appeared primarily due to differences between sampled sites in the exponentially distributed residence time $\left(1 / \mathrm{k}_{2}\right)$. These differences contributed to the dominance of mean compartmental residence time estimated by the $\mathrm{G} 2 \rightleftarrows \mathrm{G} 1$ system being apportioned to the non-exponentially distributed, age-dependent raft compartment (MRTR, Table 2). Thus, the interaction of two pools that differed due to their modelled turnover appears to be the cause of 
the age-dependent turnover from the raft as modelled by the G2 $\rightleftarrows \mathrm{G} 1$ system and portrayed in Fig. 1 .

It should be noted that the mean compartmental residence time of particles in the conceptual raft pool, MRTR, exceeds that estimated by any of the models applied to individual sampling sites. This is a consequence of the raft pool being defined as a pool of related compartments, R1 and R2 (Fig. 1), whose turnover via the particle flow paths sampled is age-dependent. Thus, the raft pool is defined by function of digesta attributes affecting flow properties of particles and not necessarily identifiable in terms of static, physical properties of rumen digesta such as 'raft', ventral digesta, large particles or small particles. In the present data, it appears that the 'raft' or age-dependent flow pool dominates the residence time of particles in the rumen digesta if the two sampling sites employed in the current study represent the flow path of all particles through the rumen digesta. Similar conclusions were found by Huhtanen \& Kukkonen (1995).

The age-dependent mean residence time for flow between dosing and sampling sites as estimated by the G2 $\rightarrow \mathrm{G} 1$ model, $2 / \lambda_{1}$, appears to be relatively unaffected by the variables studied and averaged $11.3 \mathrm{~h}$. If this is taken as an estimate of mean residence time due to slow and imperfect mixing within all digesta, then the mean residence time for age-dependent turnover from the total 'raft' pool can be estimated by deducting $11.3 \mathrm{~h}$ from MRTR for the 'raft'. This yields 19.8 and $34.1 \mathrm{~h}$ for age-independent, mass action related turnover from the 'raft' pool for ${ }^{169} \mathrm{Yb}$-labelled leaf and ${ }^{144} \mathrm{Ce}$-labelled stem respectively.

\section{Raft model}

The important concept in Sutherland's proposal (1988) is that specific gravity or the sedimentation-flotation property of a particle places it in a position where it can escape, and elegantly showed that particle size was correlated with this, rather than particle size per se necessarily being the causal factor. This is a departure from previous models based only on particle size (Baldwin et al. 1976; Poppi et al. 1981; Ellis et al. 1984b; Faichney 1986). Sutherland's concepts were simplified to a two-pool model (Fig. 1) for simplicity and to obtain an estimable non-linear model. The ability of particles to backflow into the raft perhaps via the reticulum as outlined by Sutherland (1988) is an important component not previously examined.

\section{Quantitative implications of raft model}

Two important points emerged from the present study: (1) there was a difference in the rate parameters estimated for the pools such that $\mathrm{k}_{0}>\lambda_{1}>\mathrm{k}_{2}$; (2) the VRR DM pool:raft DM pool was generally $<0 \cdot 3$, i.e. the VRR DM pool was generally $<0.23$ of the total rumen DM pool. The order of the rate parameters is important because it indicates that the raft, the pool wherein a large proportion of small particles are generated, is a slow turnover pool in the rumen $\left(\lambda_{1}\right)$, i.e. there is a long residence time of marker in this pool. It is interesting that once particles have escaped from the raft into the VRR pool they exit rapidly rather than returning in any significant proportion back into the raft $\left(\mathrm{k}_{0}>\mathrm{k}_{2}\right)$. Thus, difficulty getting out also implies difficulty getting back into the raft. Hence the small particles in the rumen do not form a homogenous pool based on their size but rather appear constrained by different attributes of each of the two pools. This is not the common view of mixing of particles within the rumen.

The probability of return can be calculated as $k_{2}$ : $\left(\mathrm{k}_{0}+\mathrm{k}_{2}\right)$ and the mean values for leaf and stem were 0.026 and 0.022 respectively. Thus, this recycling component was not very important for this data set and probably accounts for the fact that the sequential model, with no possible recycling, provided an equally good fit. However, the nature of mixing and of digestion-flotation characteristics is such that it appears important to keep this component in this model to provide more general application. In addition, diet characteristics may influence this and it would therefore be an important facet of future research. These parameter estimates are obtained from a tropical forage, which is known to have a long retention time in the rumen and digesta and that is difficult to mix by hand (D Poppi, unpublished results). High-quality temperate forages, especially legumes, are much easier to mix (D Poppi, unpublished results) and it may be that reversible flow is much higher under these circumstances. These concepts were developed by Sutherland (1988) using lucerne whilst the variables estimated in this study are derived from tropical grass leaf and stem particles.

The actual values were estimated with varying accuracy and this is reflected also in the standard errors associated with MRT in the raft and VRR which were large for the VRR. Estimates of $\mathrm{k}_{0}$ and $\mathrm{k}_{2}$ were somewhat sensitive to initial starting values used in PCNONLIN (Statistical Consultants, Inc.) but the order of parameter estimates $\mathrm{k}_{0}>$ $\lambda_{1}>\mathrm{k}_{2}$ never changes, irrespective of the order of the initial starting values, being at least 3 -fold different. It may be concluded that little reliance can be placed on some of the numerical estimates of the parameters but the order of these estimates is reliable. The order is important because that outlines the mechanism for digesta flow through the rumen and clearly identifies turnover of particles from the raft as the rate-limiting component. The order is also important because this sequence of rate constants (slow raft, fast VRR) differs from the sequence derived in particle size models (fast large particle, slow small particle) (Poppi et al. 1981; Dixon et al. 1983; Faichney, 1986) and earlier models (Blaxter et al. 1956). Some caution should be exercised in these interpretations because estimated pool size has a major influence on the estimates of residence times and rate constants.

The implications of the particle size model were that size was a factor constraining escape and that reduction in size was inversely correlated with the probability for escape (Poppi et al. 1980, 1985). Sutherland's (1988) model, however, has the concept that fermentability is a constraining factor, a factor persisting throughout particle size reduction. In support of this is the observation that most digestion of bermuda grass fibre (approximately 0.9) occurs within the rumen (McCarthy et al. 1987) a feature which must occur if flotation and sedimentation are important factors influencing escape potential of particles. Both models imply escape as the basic problem but the current 
examination of Sutherland's model specifies escape from the raft as a rate-limiting component, whereas particle size models are not specific other than identifying escape of small particles as the rate-limiting component. Thus, raft structure, consistency and properties influencing particle movement through the raft require investigation (Faichney, 1986; Bailoni et al. 1998). Vega \& Poppi (1997) have examined this by labelling faecal particles (fermentatively spent) or feed particles (large fermentative capacity) in the size range $0.5-1.12 \mathrm{~mm}$. These 'small' particles as compared with the $>1.6 \mathrm{~mm}$ used in the present study escaped at similar rates irrespective of source (feed or faeces), but the retention time was markedly influenced by the rumen conditions resulting from the type of diet which was consumed (concentrate, pelleted lucerne, pangola hay or lucerne hay). Together, these results suggest that features of the raft (size, dispersion) markedly influence retention time rather than the extent of fermentation of a particular particle.

The MRT of stem particles in the raft was longer than leaf particles and this agrees with the suggestion by Sutherland (1988) that stem particles have better buoyancy characteristics and maintain these longer than leaf characteristics. Masticated leaf and stem particles contained within nylon bags have similar digestion rates (Poppi et al. 1981) but disintegration of stem particles by digestion and detrition is slow whereas a significant proportion of leaf particles can disintegrate by this pathway (McLeod \& Minson, 1988) and these properties influence the buoyancy characteristics of stem.

The values for the proportion of the total rumen DM as raft appear high, as Dixon et al. (1983) with two steers recorded a mean value 0.54. However, their animals apparently were not fed ad libitum and Robinson et al. (1987) have shown that the raft size varies in relation to level of feeding where raft digesta weight as a proportion of total digesta weight varied from 0.42 to 0.96 as intake in cows increased from 6 to $24 \mathrm{~kg} / \mathrm{d}$. The raft in three steers offered bermuda grass hay ad libitum varied from 0.7-0.95 total rumen DM as determined by manual emptying (DP Poppi and WC Ellis, unpublished results). This estimate is comparable with that estimated by the two marker methods used here for animals grazing bermuda grass (leaf 0.75$0 \cdot 83$, stem $0 \cdot 84-0 \cdot 89$ ). The difference in raft proportion as estimated by leaf and stem markers may simply relate to the fact that there is no physical boundary to the two pools and the pools are defined as groups of particles having similar characteristics. This may be different for leaf and stem particles. In any case the raft effectively occupies most of the rumen which is greater than might be envisaged from observations on animals with restricted levels of intake (Evans et al. 1973; Dixon et al. 1983).

What needs to be considered is whether the non-raft pool, designated VRR here, is quantitatively important when it apparently accounts for a low proportion of the total MRT of marker in the rumen (0.13 leaf, 0.19 stem) and thus the raft is the primary pool of interest.

\section{Model assumptions}

Two model assumptions require clarification: (1) the nature of outflow from the VRR; (2) mixing and age dependency in changes in marker concentration in the raft. Outflow from the ventral rumen has been assigned a rate parameter, $\mathrm{k}_{0}$, and in many other passage rate studies similar values have been calculated for the whole rumen (e.g. Poppi et al. 1981). Such a representation implies that $\mathrm{k}_{0}$ is a diet characteristic and the objective in application of these models and in simulations is to use these values (determined experimentally) in a wider context. If outflow (mass/time) is a function of physiological state or energy deficit of the animal (Weston, 1996) and perhaps raft characteristics, then the rate parameter, $\mathrm{k}$, calculated is a useful numerical tool within the limits of the experiment. However, it may be limited in its wider application because its calculation is based on a pool size. What is required to be measured in relation to intake regulation is mass transport per time (a function of reticular contraction rate and mass transported per contraction) and the variation inherent in that rather than the variation in $\mathrm{k}$. The representation of digestion rate as a rate parameter is more meaningful biologically as it is independent of pool size, is a characteristic of the substrate and there are no limits on mass digested per unit time. Most biologists would agree that newly ingested particles require time to be colonized by bacteria and that the rate parameters applying to digestion and passage would change with time before reaching some plateau value. Most studies ignore this but the stochastic approach used by Matis $(1972,1984,1987)$ and Pond et al. (1988) have incorporated this. The gamma rate functions used, where the rate parameter increases with time at varying rates (different order of gamma function) up to a plateau, have been particularly useful (Pond et al. 1988). This has been used in the present study.

The question remains as to why some groups have needed to incorporate this approach whilst others have been able to ignore it. It appears that it is largely due to the method of marker introduction into the rumen and to the slow mixing (dispersion) of marker occurring between site of introduction and sampling. Those studies where marker is injected into a number of sites in the rumen minimize imperfect mixing as a component of marker dilution in the rumen or any pool with the rumen. The present study described here had large particles dosed into one discrete site in the raft. Sampling at a different site to the dosing site would lead to an ascending concentration curve as the marker dispersed throughout the pool to attain an equilibrium value. Thereafter, any further changes would only be due to disappearance of marker from the rumen and hence a descending concentration curve. This was obtained in the present study. In contrast, sampling at the bolus site would lead to an initial rapid dilution as the marker mixed and another dilution rate relating to disappearance. Employment of both dosing procedures (number of sites, single site) is in error if the aim is to examine the disappearance of a meal and both represent the extremities of the real situation.

Consumption of a labelled meal would represent the situation more realistically and where this was used (Dixon et al. 1983) exponential disappearance curves adequately explained marker disappearance. Thus, the mixing component, a feature in the present data, was not important where 


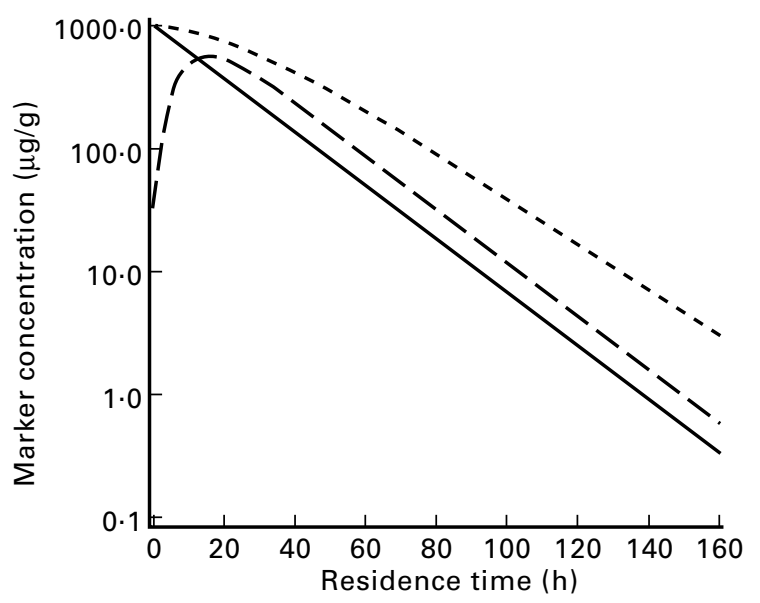

Fig. 3. Theoretical concentration curves of marker in the raft after injection of labelled bolus into raft illustrating mass action, ageindependent turnover from the dosed site, i.e. marker sampling site close to dispersing bolus (- - -), age-dependent turnover from the dosed site and/or marker sampling site separated from dispersing marker bolus (- - - ). Note the slow mixing and separation of dosing and sampling sites results in initially ascending concentrations of marker concentration as marker dispersion to the sampling site achieves equilibrium. Also note that curve $(---)$ expressing marker concentration at the sampling site would become curve $(---)$ when marker concentration is expressed as a function of total rumen digesta and the slow initial disappearance represents age-dependent turnover, i.e. particle disappearance rate is initially low and increases with time to a plateau rate parameter as distinct from dispersion functions.

a larger amount of labelled feed was injected into the rumen over a longer time period and over an effective larger number of sites as the boli are dispersed throughout the rumen during the meal (Ehrlein, 1979; Deswysen \& Ehrlein, 1981). However, if it is agreed that newly ingested particles have escape probabilities that vary with time, i.e. the longer they stay in the rumen the more they acquire desirable escape characteristics (smaller size, more completely digested and so can sediment), then a single exponential relationship would not hold. The theoretical possibilities are outlined in Fig. 3 and also were noted by Dixon et al. (1983). In their data there is a suggestion that early marker concentration values did not decline as rapidly as later points.

The importance of this is whether ignoring age dependency introduces error in estimating MRT of the overall meal in the rumen. In the data of Dixon et al. (1983) it would appear not to be great, but it is not known how universal this is, particularly as their animals were fed at restricted levels of feeding which would minimize agedependent effects. Imperfect mixing may well be a feature of very full rumens as occurs under ad libitum feeding and marker injection into a number of sites may hide a real biological phenomenon. Sutherland's concept (1988) of particle movement through the rumen also highlights a very real age-dependent process of particles losing buoyancy. Thus, caution is required in interpreting current marker studies and the desire of researchers to fit single exponential curves to this data may mask real biological processes which contribute to residence time in the rumen.
The stochastic approach of Matis (1984) offers one versatile way of incorporating this whilst Dhanoa et al. (1985) offer another based on multiple exponential pools.

This possibility is exemplified by examining the rate constants and their inverse, the MRT, associated with the descending portion of the marker concentration curve (G1 model) (Tables 1 and 2). Sampling sites (raft or ventral rumen) did not influence the values obtained but the total MRT in the rumen was greater than these values by approximately $20 \%$ (leaf) and $35 \%$ (stem). The current data set do, however, exaggerate this phenomenon by the method of dosing. The important point is that an accurate estimate of MRT is required and the MRT derived from a simple one pool exponential model may be inappropriate in some circumstances.

\section{Model validation}

Whether the raft model is an appropriate way to examine marker kinetics in the rumen is not known particularly in the separation of raft and VRR pools. Of concern is the model output indicating the size and inertness of the raft and the rapid turnover of the ventral rumen with little mixing between the two pools. Particle size models have not identified these characteristics and have assumed that particles of a particular size can move throughout the rumen.

The issue of which model to fit has implications beyond marker kinetics in the rumen. The particle size model identifies disappearance of small particles as the ratelimiting step to increasing passage rate and this can be manipulated by increasing the action of the reticulum (increasing reticular contraction rate and particles carried per contraction). The current model identifies the raft and particle entrapment within the raft as the rate-limiting component and to manipulate intake in these circumstances pool size needs to increase. This occurs in lactation, where the animal is faced with the need to increase intake to meet increasing nutrient demand.

It was concluded that the raft and the VRR appear to form two distinct pools within the rumen with particles entering the raft having escape rates that increase with time (age dependent) but which are still quantitatively slow in comparison to turnover in the VRR.

\section{Acknowledgements}

The financial assistance of BARD for this project is gratefully acknowledged. The assistance of Sandra Whitmore and M.J. Wylie is appreciated.

\section{References}

Aharoni Y, Brosch A \& Holzer Z (1999) Comparison of models estimating digesta kinetics and fecal output in cattle from fecal concentrations of single-dosed marker of particles and solutes. Journal of Animal Science 77, 2291-2304.

Bailoni L, Ramanzin M, Simonetto A, Oblakov N, Schiavon S \& Bittante G (1998) The effect of in vitro fermentation on specific gravity and sedimentation measurements of forage particles. Journal of Animal Science 76, 3095-3103. 
Balch CC \& Campling RC (1962) Regulation of voluntary food intake in ruminants. Nutrition Abstracts and Reviews 32, 669686.

Baldwin RL, Koong LJ, Ulyatt MJ \& Smith N (1976) Towards a synthesis. In Reviews in Rural Science. 2. From Plant to Animal Protein, pp. 175-181 [TM Sutherland, JR McWilliam and RA Leng, editors]. Armidale: University of New England Publishing Unit.

Bates DM \& Watts DG (1988) Nonlinear Regression Analysis and its Application. New York, NY: Wiley.

Blaxter KL, Graham NMcC \& Wainman FW (1956) Some observations on the digestibility of food by sheep, and on related problems. British Journal of Nutrition 10, 69-91.

Cruickshank GJ, Poppi DP \& Sykes AR (1990) Theoretical considerations in the estimation of rumen fractional outflow rate from various sampling sites in the digestive tract. British Journal of Nutrition 62, 229-239.

Czerkawski JW (1986) Degradation of solid feeds in the rumen: spatial distribution of microbial activity and its consequences. In Control of Digestion and Metabolism in Ruminants, pp. 158-172 [LP Milligan, WL Grovum and A Dobson, editors]. Englewood Cliffs, NJ: Reston.

Deswysen AG \& Ehrlein HJ (1981) Silage intake, rumination and pseudo-rumination activity in sheep studied by radiography and jaw movement recordings. British Journal of Nutrition 46, $327-$ 335.

Dhanoa MS, Siddons RC, France J \& Gale DL (1985) A multicompartmental model to describe marker excretion patterns in ruminant faeces. British Journal of Nutrition 53, 663-671.

Dixon RM, Kennelly JJ \& Milligan LP (1983) Kinetics of $\left[{ }^{103} \mathrm{Ru}\right]$ phenanthroline and dysprosium particulate markers in the rumen of steers. British Journal of Nutrition 49, 463-473.

Egan JK \& Doyle PT (1984) A comparison of particulate markers for the estimation of digesta flow from the abomasum of sheep offered chopped oaten hay. Australian Journal of Agricultural Research 35, 279-291.

Ehrlein HJ (1979) Motility of the Forestomachs in Ruminants. Gottingen: Institut Wiss, Film.

Ellis WC, Bailey EM \& Taylor CA (1984a) A silicone esophageal cannulae: Its surgical installation and use in research with grazing cattle, sheep or goats. Journal of Animal Science 59, 204-209.

Ellis WC, Lascano C, Guerrero J, Pond K \& Matis JH (1982) Particle size degradation in and escape from the rumen. Federation Proceedings 41, 343.

Ellis WC, Matis JH, Hill TM \& Murphy MR (1994) Methodology for estimating digestion and passage kinetics of forages. In Forage Quality, Evaluation and Utilization, pp. 81-95 [GC Fahey, editor]. Madison, WI: American Society of Agronomy Inc, Crop Science Society of America Inc., Soil Science Society of America Inc.

Ellis WC, Matis JH, Pond KR, Lascano CE \& Telford JP (1984b) Dietary influences on flow rate and digestive capacity. In Herbivore Nutrition in the Subtropics and Tropics, pp. 269-293 [FMC Gilchrist and RI Mackie, editors]. Craighall: The Science Press.

Ellis WC, Matis JH, Pond KR \& Magloogi M (1985) Physical and chemical digestion of forage fragments with emphasis on stochastic, hetergeneous rate models. In Proceedings of the Second International Symposium on Modeling Ruminant Digestion and Metabolism, pp. 34-42 [RL Baldwin and AC Bywater, editors]. Davis, CA: Department of Animal Science, University of California.

Evans EW, Pearce GR, Burnett J \& Pillinger SL (1973) Changes in some physical characteristics of the digesta in the reticulo- rumen of cows fed once daily. British Journal of Nutrition 29, 357-376.

Faichney GJ (1975) The use of markers to partition digestion within the gastro-intestinal tract of ruminants. In Digestion and Metabolism in the Ruminant, pp. 277-291 [IW McDonald and ACI Warner, editors]. Armidale: University of New England Publishing Unit.

Faichney GJ (1986) The kinetics of particulate matter in the rumen. In Control of Digestion and Metabolism in Ruminants, pp. 173-195 [LP Milligan, WL Grovum and A Dobson, editors]. Englewood Cliffs, NJ: Reston.

Faichney GJ \& Boston RC (1983) Interpretation of the faecal excretion pattern of solute and particle markers introduced into the rumen of sheep. Journal of Agricultural Science, Cambridge 101, 575-581.

France J, Thornley JHM, Dhanoa MS \& Siddons RC (1985) On the mathematics of digesta flow kinetics. Journal of Theoretical Biology 113, 743-758.

Grovum WL \& Williams VJ (1973a) Rate of passage of digesta in sheep. 3. Differential rates of passage of water and dry matter from the reticulo-rumen, abomasum and caecum and proximal colon. British Journal of Nutrition 30, 231-240.

Grovum WL \& Williams VJ (1973b) Rate of passage of digesta in sheep. 4. Passage of marker through the alimentary tract and the biological relevance of rate constants derived from the changes in concentration of marker in faeces. British Journal of Nutrition 30, 313-329.

Grovum WL \& Williams VJ (1977) Rate of passage of digesta in sheep. 6 . The level of food intake on mathematical predictions of the kinetics of digesta in the reticulo-rumen and intestines. British Journal of Nutrition 38, 425-436.

Huhtanen P \& Kukkonen U (1995) Comparison of methods, markers, sampling sites and models for estimating digesta passage kinetics in cattle at two levels of intake. Animal Feed Science and Technology 52, 141-158.

Hungate RE (1966) The Rumen and its Microbes. New York, NY: Academic Press.

Kennedy PM \& Murphy MR (1988) The nutritional implications of differential passage of particles through the ruminant alimentary tract. Nutrition Research Reviews 1, 189-208.

Lascano CE (1979) Determinants of grazed forage voluntary intake. PhD Thesis, Texas A\&M University.

McCarthy DB, Ellis WC \& Worley RR (1987) Digestion of fiber in segments of the bovine gastrointestinal tract. Journal of Animal Science 65, Suppl. 1, 340.

McLeod MN \& Minson DJ (1988) Large particle breakdown by cattle eating ryegrass and alfalfa. Journal of Animal Science 66 , 992.

Matis JH (1972) Gamma time dependency in Blaxter's compartmental model. Biometrics 28, 597-602.

Matis JH (1984) Modeling ruminant digestion and metabolism. In Proceedings of the Second International Workshop, University of California, Davis, pp. 10-15 [RL Baldwin and AC Bywater, editors]. Davis, CA: Department of Animal Science, University of California.

Matis JH, Wehly TE \& Metzer CM (1983) On some stochastic formulations and related statistical moments of pharmacokinetic models. Journal of Pharmacokinetics and Biopharmacentics 11, 77-92.

Matis JH (1987) The case for stochastic models of digesta flow. Journal of Theoretical Biology 124, 371-376.

Pond KR, Ellis WC, Matis JH, Ferreiro HM \& Sutton JD (1988) Compartment models for estimating attributes of digesta flow in cattle. British Journal of Nutrition 60, 571-595.

Poppi DP, Hendricksen RE \& Minson DJ (1985) The relative resistance to escape of leaf and stem particles from the rumen of 
cattle and sheep. Journal of Agricultural Science, Cambridge 105, 9-14.

Poppi DP, Norton BW, Minson DJ \& Hendricksen RE (1980) The validity of the critical size theory for particles leaving the rumen. Journal of A gricultural Science, Cambridge 94, 275-280.

Poppi DP, Minson DJ \& Ternouth JH (1981) Studies of cattle and sheep eating leaf and stem fractions of grasses. III. The retention time in the rumen of large feed particles. Australian Journal of Agricultural Research 32, 123-127.

Robinson PH, Tamminga S \& Van Vuuren AM (1987) Influence of declining level of feed intake and varying the proportion of starch in the concentrate on rumen ingesta quantity, composition and kinetics of ingesta turnover in dairy cows. Livestock Production Science 17, 37-62.

Spillane KT \& Minson DJ (1986) On Modelling the Passage of Digesta Particulates in Sheep. Tropical Agronomy Technical Memorandum. no. 49. St Lucia: CSIRO Division of Tropical Crops and Pastures.

Sutherland TM (1988) Particle separation in the forestomachs of sheep. In Aspects of Digestive Physiology in Ruminants, pp. 43-73 [A Dobson, editor]. Ithaca, NY: Cornell University Press.

Thornton RF \& Minson DJ (1973) The relationship between apparent retention time in the rumen, voluntary intake, and apparent digestibility of legume and grass diets in sheep. Australian Journal of Agricultural Research 24, 889-898.

Ulyatt MJ, Blaxter KL \& McDonald I (1967) The relations between the apparent digestibility of roughages in the rumen and lower gut of sheep, the volume of fluid in the rumen and voluntary feed intake. Animal Production 9, 463-470.

Ulyatt MJ, Dellow DW, John A, Reid CSW \& Waghorn GC (1986) Contribution by chewing during eating and rumination to the clearance of digesta from the reticulorumen. In Control of Digestion and Metabolism in Ruminants, pp. 498-515 [LP Mulligan, WL Grovum and A Dobson, editors]. Englewood Cliffs, NJ: Reston.

Vega A \& de Poppi DP (1997) Extent of digestion and rumen condition as factors affecting passage of liquid and digesta particles in sheep. Journal of Agricultural Science, Cambridge 128, 207-215.

Weston RH (1996) Some aspects of constraint to forage consumption by ruminants. Australian Journal of Agricultural Research 47, 175-197.

Waghorn GC, Reid CSW, Ulyatt MJ \& John A (1986) Feed comminution, particle composition and distribution between the four compartments of the stomach in sheep fed chaffed lucerne hay at two feeding frequencies and intake levels. Journal of Agricultural Science, Cambridge 106, 287-296.

Wylie MJ, Ellis WC \& Matis JHBailey EMJames WDBeever DE (2000) The flow of forage particles and solutes through segments of the digestive tracts of cattle. British Journal of Nutrition 83, 295-306.

\section{Appendix}

Solution of model equations from gamma 2 rate functions

Definitions:

$\mathrm{X}_{\mathrm{R} 1}(\mathrm{t}), \mathrm{X}_{\mathrm{R} 2}(\mathrm{t})$ is the marker in dosing and sampling sites of raft pool respectively;

$\mathrm{X}_{\mathrm{v}}(\mathrm{t})$ is the marker in VRR pool;

$V_{R}, V_{v}$ is the quantity of DM in raft and VRR pools respectively (assumed constant over time);

$C_{R 1}(t), C_{R 2}(t)$ is the concentration of marker in dosing and sampling sites of raft respectively;

$\mathrm{C}_{\mathrm{v}}(\mathrm{t})$ is the concentration of marker in VRR pool;
$\dot{\mathrm{X}}_{\mathrm{i}}(\mathrm{t}), \dot{\mathrm{C}}_{\mathrm{i}}(\mathrm{t})$ is the derivatives of $\mathrm{X}_{\mathrm{i}}(\mathrm{t})$ and $\mathrm{C}_{\mathrm{i}}(\mathrm{t})$;

$\lambda_{1}, \mathrm{k}_{0}, \mathrm{k}_{2}$ is the rate parameters for escape from raft, escape from VRR to omasum, and backflow from VRR to raft respectively;

$\mathrm{r}$ is the $\mathrm{V}_{\mathrm{v}} / \mathrm{V}_{\mathrm{R}}$, which is the ratio of quantities (VRR:raft);

$K$ is the coefficient matrix;

MRTR, MRTV is the MRT in raft and VRR respectively;

MRTT is the MRT in total system.

Equations:

$$
\begin{gathered}
\dot{\mathrm{X}}_{\mathrm{R} 1}(\mathrm{t})=-\lambda_{1} \mathrm{X}_{\mathrm{R} 1}(\mathrm{t}), \\
\dot{\mathrm{X}}_{\mathrm{R} 2}(\mathrm{t})=-\lambda_{1} \mathrm{X}_{\mathrm{R} 2}(\mathrm{t})+\lambda_{1} \mathrm{X}_{\mathrm{R} 1}(\mathrm{t})+\mathrm{k}_{2} \mathrm{X}_{\mathrm{v}}(\mathrm{t}), \\
\dot{\mathrm{X}}_{\mathrm{v}}(\mathrm{t})=-\left(\mathrm{k}_{0}+\mathrm{k}_{2}\right) \mathrm{X}_{\mathrm{v}}(\mathrm{t})+\lambda_{1} \mathrm{X}_{\mathrm{R} 2}(\mathrm{t}), \\
\dot{\mathrm{C}}_{\mathrm{R} 1}(\mathrm{t})=\dot{\mathrm{X}}_{\mathrm{R} 1}(\mathrm{t}) / \mathrm{V}_{\mathrm{R}}=-\lambda_{1} \mathrm{C}_{\mathrm{R} 1}(\mathrm{t}), \\
\dot{\mathrm{C}}_{\mathrm{R} 2}(\mathrm{t})=\dot{\mathrm{X}}_{\mathrm{R} 2}(\mathrm{t}) / \mathrm{V}_{\mathrm{R}}=-\lambda_{1} \mathrm{C}_{\mathrm{R} 2}(\mathrm{t})+\lambda_{1} \mathrm{C}_{\mathrm{R} 1}(\mathrm{t})+\mathrm{k}_{2} \mathrm{rC} \mathrm{v}(\mathrm{t}), \\
\dot{\mathrm{C}}_{\mathrm{v}}(\mathrm{t})=\dot{\mathrm{X}}_{\mathrm{v}}(\mathrm{t}) / \mathrm{V}_{\mathrm{v}}=-\left(\mathrm{k}_{0}+\mathrm{k}_{2}\right) \mathrm{C}_{\mathrm{v}}+\lambda_{1} \mathrm{C}_{\mathrm{R} 2}(\mathrm{t}) / \mathrm{r} .
\end{gathered}
$$

These linear differential equations yield non-linear regression models. The parameter estimation for such models requires specialized statistical software (Bates \& Watts, 1988). This study used PCNONLIN (Statistical Consultants Inc.) which utilizes numerical integration to solve the differential equations.

Residence time denotes the elapsed time accumulated by a particle during all of its visits to a site, i.e. residence time is the sum of one or more retention times. Matis et al. (1983) show that the mean residence times are given by $K^{-1}$, where $K$ is the matrix of rate coefficients. For this model, one has:

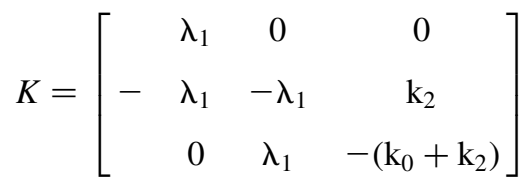

and

$$
-K^{-1}=\left[\begin{array}{ccc}
\mathrm{a}_{1} & 0 & 0 \\
\mathrm{a}_{2} & \mathrm{a}_{2} & \mathrm{a}_{3} \\
\mathrm{a}_{4} & \mathrm{a}_{4} & \mathrm{a}_{4}
\end{array}\right],
$$

where

$$
\begin{gathered}
\mathrm{a}_{1}=\lambda_{1}^{-1}, \\
\mathrm{a}_{2}=\left(\mathrm{k}_{0}+\mathrm{k}_{2}\right) /\left(\mathrm{k}_{0} \lambda_{1}\right), \\
\mathrm{a}_{3}=\mathrm{k}_{2} /\left(\mathrm{k}_{0} \lambda_{1}\right),
\end{gathered}
$$

and

Hence

$$
\mathrm{a}_{4}=\mathrm{k}_{0}^{-1} \text {. }
$$

$$
\begin{gathered}
\text { MRTR }=\mathrm{a}_{1}+\mathrm{a}_{2}=\left(2 \mathrm{k}_{0}+\mathrm{k}_{2}\right) /\left(\mathrm{k}_{0} \lambda_{1}\right), \\
\text { MRTV }=\mathrm{a}_{4}=\mathrm{k}_{0}^{-1},
\end{gathered}
$$

MRTT $=$ MRTR + MRTV $=\left(2 \mathrm{k}_{0}+\lambda_{1}+\mathrm{k}_{2}\right) /\left(\mathrm{k}_{0} \lambda_{1}\right)$. 